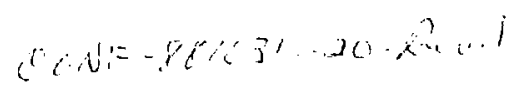

UCRL- 98670 ReV. 1
PREPRINT

$$
\begin{aligned}
& f \cdots \cdots
\end{aligned}
$$

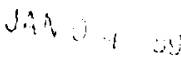

\title{
A NON-INDUCTIVELY DRIVEN TOKAMAK REACTOR BASED ON ITER
}

\author{
M.E. Fenstermacher, R.S. Devoto \\ R.H. Bulmer, J.D. Lee, J.R. Miller \\ j.H. Schultz
}

\section{This paper was prepared for submittal to the \\ 8th Topical Meeting on the Technology of \\ Fusion Energy \\ Salt Lake City, Utah \\ October $9-13,1988$}

December, 1,1988

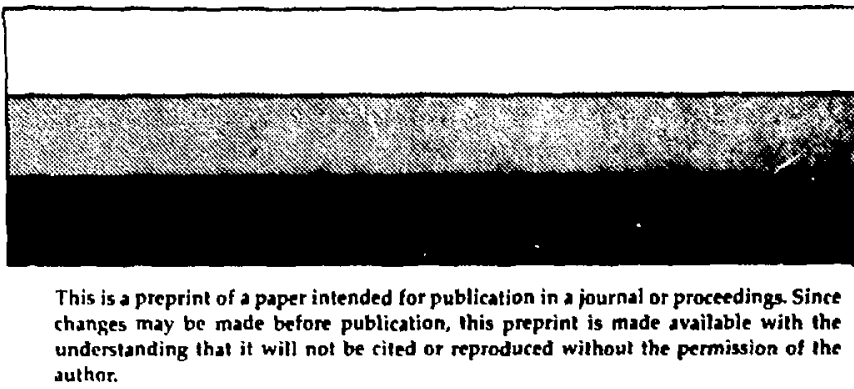
author.

\section{DISCLAIMER}

This report was prepared as an account of work sponsored by an egency of the United States Government. Neither the United States Government nor any agency thereof, nut any of their employees. makes any warranty. express or insplied, or assumes any legal liability or responsihility for the accuracy, completeness, ar usefulness of any information, upparatus, product, or process disclosed, of tepresents that its use would not infinge privalely owned rights. Reference herein to any specific commerclal product, process, or service by trade name, 1rademufk. manufacturer, or otherwise does not necessatily constitute or imply its endorsement, recom. mendation, of favoring by the United States Government or any agency thereof. The views and apinions of authars expressed herein do not necessarily state of reflect those of the United States Government or any agency thereuf.

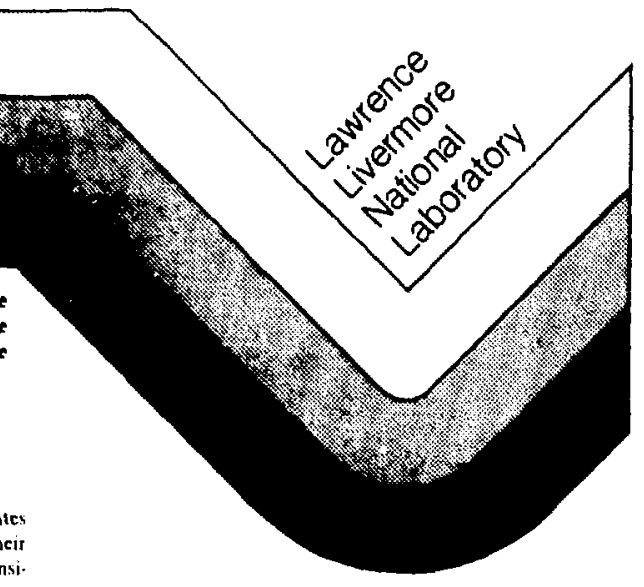

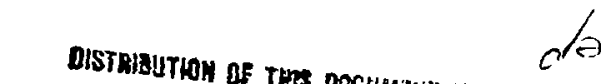

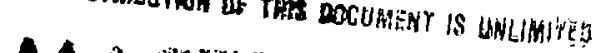


M. E. Fensternacher, R. S. Devoto, R. H. Bulmer, J. D, Lee; J, R. M1ller

Lawrence Livermore National Labozatory, Livermore CA 94550

(415) $423-6308$

\section{ABSTRACT}

The physics and engineering guidelines for the ITER device are shown to lead to viable physics operating points for a steady state tokamak power reactor. Non-inductive current drive is provided in steady state by high enerzy neutral beam injection in the plasma core, lower hybrid slow waves in the outer regions of the plasma and bootstrap current. Plasma gain $Q$ (-fusion power/input power) in excess of 20 and average neutron wall loading, $\langle\Gamma\rangle=2.0 \mathrm{~mW} / \mathrm{m}^{2}$ are predicted in a device with major radius, $R_{0}$ $-7.5 \mathrm{~m}$ and minor radius, a $-2.8 \mathrm{~m}$.

\section{INTRODUCTION}

The terms if reference [1] for the International Thermonuclear Experimental Reactor (ITER) state that ITER should demonstrace "technologies essential to a reactor in an Integrated system." In addition, ITER "will provide the data base in physics and technology necessary for the design and construction of a demonstration fuston power plant." Part of the process of connecting ITER wth a demonstration power plant is to perform parametric variations of steady state reactor configurations using the same current drive scenarios envisaged for ITER. At present, high energy negative-ion neutral beam injection (NBI) for current drive in the plasma core supplemented with lower hybrid (LH) slow wave current drive on the outer flux surfaces and bootstrap current, Is the favored current drive scenario for the ITER design in steady state. The goal of this paper is to show that this current drive concept leads to plasma physics parameters which approach those required for a viable power producling reactor.

The neutral bears must drive current in the plasme core boch to furnish the seed current
J. H. Schultz,

Plasma Fusion Center, MIT

175 Albany St., NW17-221

Cambridge MA 01239

(617) $253-8151$

necessary to produce bootstrap current and because the $L H$ waves can not penetrate to the Bxis in a reactor Brade plasma. To assure penetration, the neutral boam energy, $E_{n b}$, is chosen to yield about a flve a-fold reduction in beam current along the full beam path through the plasma. Injection tangential to the magnetic axis is used to maximize the current drive efficiency while maintaining sufficient current drive near the axis. Lower hybrid waves propagate only part of the way into the plasma from the outer edge because of a combination of an accessibllity condition (primarily a function of plasma density) and a condition for avolding strong quasi-linear electron Landau damping of the wave (a function of the plasma temperature). For reactor grade plasmas with peak electron density, $\dot{n}_{0} \approx i 0^{20} \mathrm{~m}^{-3}$, and temperature, $t_{0} \approx$ $25 \mathrm{keV}$, the $\mathrm{LH}$ waves penetrate only to a normalized minor radius $r / a=0.7$.

The remainder of this paper is organized as follows. In section II we present the physics and engineering relations which limit the avaliable parameter space for acceptable reactor operating points, We describe a convenient method for examining possible operating apace subject to these constralnts in section III. Results are presented in section IV Including trade-offs in device perforance for vartous operating points and the effect of various assumptions on the avallable operating space, Section V presents our conclusions.

\section{CONSTRAINING RELATIONS}

A fundamental limitation on plasme parametera is the crittcal toroldal beta beyond which the plasma is expected to becone unstable to Ideal ballooning or kink nodes. This linit is conveniently expressed in teros of the Troyon formula [2]

$$
\beta \leq \beta_{\mathrm{T}}=\mathrm{C}_{\mathrm{T}} \mathrm{I}_{\mathrm{P}} / \mathrm{a} \mathrm{B}_{\mathrm{O}}
$$


where $I_{p}$ is the plasma current, a is the minor radius, $B_{0}$ is the toroldal fleid at the geometric major radius $R_{0}$, and $C_{T}$ is a coefflctent, typically $3 \&$, whlch sets the upper IImic on $\beta$. MRS unlts are used throughout this paper except for current in MA and temperature in keV. In addition, theoretical studies of ideal kink stablitty show that the plasma is likely to be unstable to $n-1$ kinks if the edge safety factor 9 , drops below about 3.0. It should be noted that some experiments have been able to achieve stable operation at $q_{*}$ approaching 2.5. The safety factor is given by

$$
q_{*}-B_{0} R_{0} \oint\left\{d s / R^{2} B_{p}\right)
$$

with $B_{p}$ the local poloidal fleld, and $R$ the major radial coordinate. The limit on $q_{t}$ is typically applied where the pololdal flux is 95 of the total flux enclosed by the separatrix. The 1101t becomes $q_{q s}>3.0$. Since it is necessary to compute the 2-D HHD equilibrium to find the value of $q_{9 y}$, it is desirable to have a siople formula for safety factor. We use the form

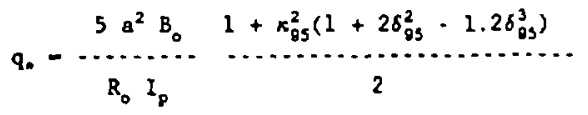

where $x_{05}$ is the elongation and $\delta_{95}$ is the criangularicy of the 95 flux surface. Since $q$. is typlcally less than $\mathrm{Qgg}_{\mathrm{gg}}$, we should take our IImit lower than 3.0 , but we to not yet have sufficient information to choose a precise number. There are additional conditions on $x_{85}$ and $\delta_{9 g}$ typlcally $\kappa_{g s}<2.5$ and larger $\delta_{9 s}$ required at larger $\kappa_{9 s}\left(\delta_{g s}=0.5\right.$ at $\left.\kappa_{9 s}=2.5\right)$.

For the density limit we use the Greenwald 11mit [3], given by

$$
\bar{r}_{.} \leq \bar{r}_{G r}-f_{G r} \kappa_{g s} I_{p} / A_{p}
$$

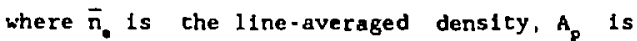
the plasma cross sectional area and the coefficlent $f_{G r}$ is taken as 1.0. He note that the density limit is caken to be a "soft" $11 \mathrm{mit}$ In the ITER design process. Recent experiments and analysis have shown chat operation near this density does not, by itself, imply that the frequency of disruptions Increases. In practice, this limit should seldow be approached in steady state operation.

A varlecy of scaling laws are possible for energy confinement time. We use one of the models currently used for the ITER studies, namely the relation proposed by Goldston [4].

${ }_{T}{ }_{G}=0.037 I_{p} R_{0}^{1.75} \kappa_{Q S}^{0.5} P_{h}^{-0.5} a^{-0.37}\left(A_{1} / 1.5\right)^{0.5}$ where $A_{1}$ is the average plasma mass, and the total heating power $P_{h}$ is the sum of the current-drive power and the alpha power less the radlated power.

It Is widely belleved that the energyconfinement time cannot exceed the ohmlc, or neo-Alcator time given by [5]

$$
r_{M A}-0.0625 \bar{n}_{0} \text { a } R_{0}^{2} q_{.}
$$

In practice, ' $\mathrm{Ha}$ 13 always greater than ${ }^{t} \mathrm{G}$ under predicted steady state conditions for reactor sized devices. To assure that the confinement time used in our study does not excoed 'HA' we

use the formula, $r_{2}-\left(r_{M}^{-10}+\left(\mathrm{Hr}_{0}\right)^{-10}\right]^{-0.1}$ where $H$ is described below.

The Goldston scaling was developed for $L$ mode discharges in Iimiter plasmas. It was recently noticed that L-mode discharges in divertor plasmas in JET [6] displayed somewhat better confinement tiwe, perhaps as wuch as $50 t$ higher than the value predicted by $r_{G}$. For these studies we therefore compute $r_{z}$ using the prediction from Eq. (5) multiplied by a constant $\mathrm{K}=1.5$.

At present, the likely candidates for nonInductive current drive are lower hybrid (LH) slow waves in the outer region of the plasma, high-energy neutral beams (NB) In the core, and neoclassical (bootstrap) current. The $L$ waves are linited to the outer region because the cholce of $N_{11}$ dictated by the accessibliticy condition means that the waves are strongly Landau damped on electrons in the outer plasma region whore the temperature reaches $10-15 \mathrm{keV}$ [7]. The accessibility condition is given by

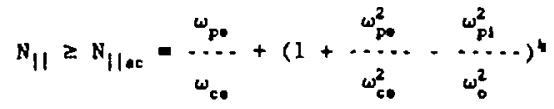

where $\omega_{p j}$ and $\omega_{c J}$ are the local plasma and cyclotron frequencies of species $f$ and $\omega_{p}$ is the frequency of the launched waves. The condition for strong electron landau damping can be written approximately as (7)

$$
N_{11} \leq N_{11}^{E D}-7 / T_{?}^{4}(r)
$$

In our calculations of the power required for current drive, we choose $N_{\text {II }}$ at the radius of maximum penetration into the plasma, $r_{\max }$, to satisfy both of these conditinns. The required power is reported in the forw of a current-drive figure of merit

$$
\gamma_{1 b}=n_{-20}\left(r_{\max }\right) I_{L h} R_{D} / P_{L h}
$$


where $n_{620}\left(r_{\max }\right)$ is the electron density at $r_{\max }$ in units of $10^{20} \mathrm{~m}^{-3}$, and $I_{\mathrm{Ih}}$ and $P_{1 \mathrm{~s}}$ are the lower hybrid driven current and absorbed power, respectively. To compute $\boldsymbol{r}_{2 \mathrm{r}}$ we use the expression due to Fisch [8], wultiplied by an adjustment factor to bring it inco agreement with detalled calculations of ray cracing and power deposicion 19 \}. Ttis corrrection factor is typically 0.6 .

For the NB figure of merit we employ an expression which can be obtained from an analytic expression for the fast lon distribution function (10). The expression reads

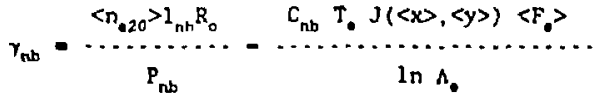

where $T$, is the densicy-welghted volume averaged electron temperature, $<>$ denates a volume average aud $J(x, y)$ is a function which takes Into account the appropriate moment. of the fast ion distribution function. It is approximated by [11]

$J(x, y)=x^{2} /\left[4+3 y+x^{2}\left(x+2.39+0.61 y^{0.7}\right)\right]$

$x^{2}-E_{b} / E_{c}, y-\left(\Sigma_{1} l n \Lambda_{1} n_{1} z_{1}^{2} / A_{b}\right) /\left(3 \Sigma_{1} \ln \Lambda_{1} n_{1} z_{1}^{2} / A_{1}\right)$. $A_{b}$ is the beam mass in amu, $E_{b}$ is the NB energy. In $\Lambda_{\text {. }}$ and In $\Lambda_{1}$ are the Coulomb logarithms for electrons and lons respectively, and $C_{b b}$ is a correction factor (typically 3.4) to fit the detailed calculations of beam deposition and fast ion current performed with the ACCOME code [12). $\angle F>$ is tine ratio of the net current to the total fast ion current, which accounts for the partial cancellation of the fast-ion current by the electrons. To calculate $\langle F\rangle$ we use a scaling formula 111 ,

$\left\langle F_{\theta}\right\rangle-1-\left(Z_{D} / Z_{0 t \varepsilon}\right)\left(1-G\left(\langle\epsilon\rangle, Z_{* f t}\right)\right)$

where

$\left.G\left(<e>. z_{\text {otg }}\right)=\left(1.55+0.85 / z_{\text {tet }}\right)<e\right\rangle^{4}$.

$$
\left.\left(0.2+1.55 / 2_{\text {of }}\right)<e\right)
$$

and $\langle c\rangle$ is an effective inverse aspect ratio. Detalled calculations of AB current drive (12) Indicate that Eq. (13) should be evaluated with $\langle r\rangle=0.46 a / R_{0}$.

The neutral beam energy is set by the requiremenc that the beaws penetrate sufficlently close to the plasma axts to produce an MHD stable current profile there. From calculations of beam attenuation, including excitation-enhanced stopping cross sections [13], the following scaling formula has been developed for the beam energy required.

$$
\begin{aligned}
& E_{n b}(\mathrm{MeV} / \mathrm{amu})-\left(1.37 \times 10^{-23}\left(z_{\text {orf }}+0.2\right)^{0.65}\right. \\
& \left.\left[3 \dot{n}_{0} /\left(0.2 t_{*}+1.0\right)\right]^{0.118} \bar{T}_{0} L / T_{b}\right\}^{\varepsilon}
\end{aligned}
$$

where $\xi-\left(0.7+0.022_{\text {off }}\right)^{-1}$, L Is the bear path length from the plasma edge to the cangency point, and $r_{b}$ is the number of e-fold reductions in beam current over the path $L$. For this study, we have used ${ }_{b}-2.4$ in thls formula based on our initial calculations of NB current drive.

The geometry of the tokanak reactor considered in this study is simllar to the ITER design. The Inner radial bulld Includes a central oH coll stack, TF coll innor log, and flrst wall + blanket + shield. Tho outer bore of the oH call stack was constrained to be $R_{\text {of }} \leq$ $2.0 \mathrm{~m}$. The elongation and trlangularity on the 95 flux surface were set to $x_{9 g}-2.0$ and $\delta_{93}-$ 0.4 respectively. A central toroldal field, $B_{0}$ - 6.0 T, was chosen based on a target constraint of about $14 \mathrm{~T}$ maximum fleld on the $T F$ inner $1 \mathrm{eg}$, although maximum field by itself is not regarded as a fundamental constraint. Fixed parameters for our reference device are given in Table 1.

Table 1. Reference case parameters.

$$
\begin{array}{ll}
R_{0}=7.5 \mathrm{~m} & B_{0}=6.0 \mathrm{~T} \\
a=2.8 \mathrm{~m} & a_{n}=1.0 \\
\kappa_{99}\left(\kappa_{0}\right)=2.0(2.2) & a_{T}=0.5 \\
\delta_{95}\left(\delta_{\phi}\right)-0.4(0.6) & \text { Deuterlum beams }
\end{array}
$$

Another part of the radial build is the Inboard first wall/blariket/shield and their associated mantfolding and gaps. The thickness of chese components is a function of the blanket type used. Based on work summarlzed in $\{14$. this thickness varles between 1.07 and 1.28 m over a range of blanket types. The thinnest case is for a water-cooled $\mathrm{LALO}_{2} / \mathrm{Be}$ blanket while the thickest case is for a $\mathrm{LI}$ self-cooled blanket. For this work we will employ a He cooled $\mathrm{Li}_{2} \mathrm{O}$ blanket with a first wall/blanket/shiald total inboard radial bulld thickness of $1.16 \mathrm{~m}$

- The TF and PF magnet systems have been designed on the basis of several engineering constraints that ensure their rellabllity, protection, and structural integrity. These include, sufficlent current and temperature margins of the conductor in the high field regions of the colls for good stabllity, an 
upper limit on the hot-spot temperature in a coll during quench and dump of $150 \mathrm{~K}$ (with $20 \mathrm{kV}$ retminal voltage during dump), and maximum combined stresses at any point in the case or windings which are within allowables for the materlals involved. Table 2 . summarizes features of the TF system for the present study. It is a direct, non-optimized extrapolation of present ITER design guldelines. The aximum von Mises stress estinated in the nose region of the wedged TF cases is $670 \mathrm{MPa}$.

Table 2. TF System Paraneters

Number of colls

16

Total current

$225 \mathrm{MA}$

Winding pack geometry

Cross-section (approx.) (1.15 $\mathrm{m} \times 0.61 \mathrm{~m})$

Hean radius of the inboard leg $2.9 \mathrm{~m}$

Mean radius of the outboard leg 13.0 四

Nean helght above the midplane 8.9 m

Total TF system stored energy $105.3 \mathrm{GJ}$

Maximum field at the windings $\quad 14.3 \mathrm{~T}$

Winding pack current density $21.2 \mathrm{~A} / \mathrm{mm}^{2}$

Total TF system cold mass $\quad 10,400 \mathrm{t}$

Conductor descrip. ( $\mathrm{Nb}_{3} \mathrm{Sn}$, cable-in-condult) Operating currenc $\quad 32.9 \mathrm{kA}$ Critical current $\quad 54.8 \mathrm{kA}$

Current sharing temperature $6.2 \mathrm{~K}$

Effective area of a turn $\quad 1552 \mathrm{~mm}^{2}$

Area of steel in the conduit $\quad 666 \mathrm{~mm}^{2}$

Area of insulation around condutt $1.54 \mathrm{~mm}^{2}$

Area of conductor inside condult $439 \mathrm{~mm}^{2}$

Area of helium Inside condult $293 \mathrm{~mm}^{2}$

Fraction of copper in conductor 0.67

The PF system is a closer extrapolation of the present ITER design since the critical central solenoid is essencially unchanged ( 1.4 in inner radius and 2.0 outer radius). The present design provides a volt-sec capability similar to ITER but the rotal stared energy is higher, $W_{\mathrm{pr}}-12 \mathrm{GJ}$. The increase results from the increased radif of the divertor and equilibrium field solenoids. Design of the PF system is considerably eased by the dramatic reduction in fatigue cycles and ac losses in this steady state device, compared with ITER which must be designed to operate in pulsed ignited mode.

Combining these components of the radial bulld places the radius of the first wall on the inboard side at approximately $R_{\mathrm{pw}} \geq 4.5 \mathrm{~m}$. With this constraint, we chose a geometric major radius, $R_{0}-7,5 m$ and a plasma minor radius, $a$ $-2.8 \mathrm{~m}$. The inner scrapeoff layer thlckness is $\Delta_{1}-0.2 \mathrm{~m}$. A typical set of equilibrium tiux contours for this device operating with coroldal current, $I_{p}-25 \mathrm{MA}$, is shown in Fig. 1 .

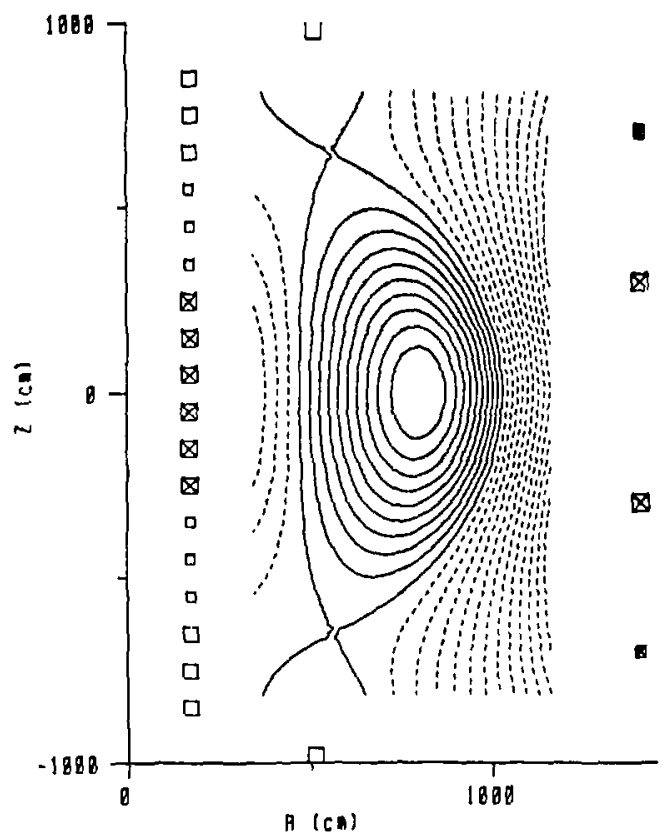

Figure. 1. Equilibrium flux contours for the baseline case.

\section{STEADY STATE OPERATING GONTOURS (SOPCON'S)}

We nave found that plots of performance parameters (eg. Q fusion power/current drive power, $\langle\Gamma\rangle$ - average neutron wall load, and current-drive power, $\left.P_{c d}-P_{1 h}+P_{n b}\right)$, in the $I_{p} \cdot C_{\tau}$ plane are conventent for comparing steady state operating points. We refer to these sceady state OPerating contour plots as sopCONs. One such SOrCON, is shown in F1g. 2.

The power balances for electrons and lons are performed separately for each point on the sopCoN. Alpha power and current drive power are balanced against cransport losses and radiation power (Bremsitrahlung and symchrotron). Transport losses are calculated using emplrical energy conflnement scaling laws for $T_{E}$. These equations determine the electron and Ion temperatures. For a fixed conflguration, each point in $I_{P}-C_{T}$ space corresponds to a unique 


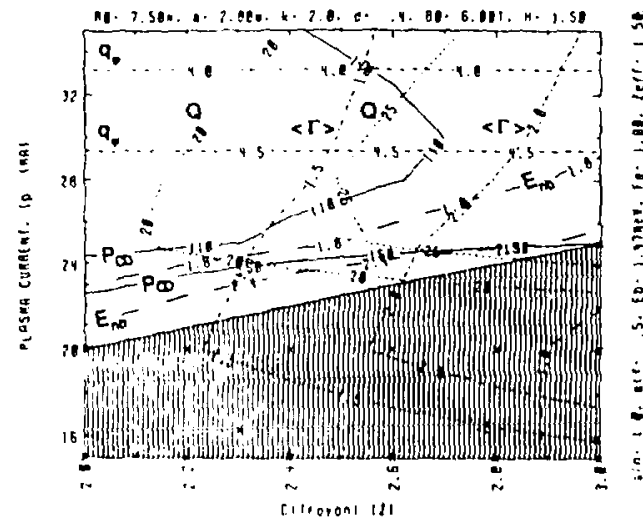

Figure. 2. SOPCON for the baseline case.

value of beta through the Troyon formula. This uniquely determines the plasma density at power balance. These equations and the other physics expresslons described above are incorporated Into the MUMAK code [15].

Radial profiles of the densicy and temperature are taken to be of the forts, $X(r)$ $x(0)\left(1-(r / a)^{2}\right\}^{\alpha} x$ where $x-n, T$. Power balance terws in MUAK are Integrated over these model profiles using a circular flux surface model to yleld profile correction factors. The volure of the Eully shaped plasma is used to compute the magnitude of the power balance terms.

\section{RESULTS AND DISGUSSION}

Fixed parameters for our reference device are given in table 1 . The major radius and aspett ratio are consistent with the ITER engineering design guldelines. Optimlzation of the device geometry for reactor performance or minimum cost has not been done. The SOPCON for this reference case is shown in Fig. 2. Goldston energy confinement scaling with an enhancement factor, $H=1.5$ (1imited by the NeoAlcator confinewent $t$ ime), has been used. The shaded region shows where the denstty for power balance exceeds the Greenwald densicy limit. The density and temperature profile exponents are $a_{n}-1.0$ and $a_{2}-0.5$ respectively (the same pressure profile as in ITER), and the plasma effective charge is taken to be $z_{\text {off }}-1.5$ with oxygen Impuricy. We have adopted the incerim ITER guideline for bootstrap current fraction, $I_{b s} / I_{p}-0.3$, though higher fractions may be possible in scenarios with high poloidal beta $\left(\beta_{p} \geq 1.0\right)$.

Contours shown on the SOPCON Inelude $Q-20$ and $25, P_{C D}-110$ and $150 \mathrm{MW}, q_{\mathrm{gS}}-4.0$ and 4.5 (scaled from the MHD calculation at $I_{p}-25$ MA shown in FIg. 1), $E_{b}-1.8$ and $2.4 \mathrm{MeV}^{p}$, and $\langle\Gamma$ -1.5 and $2.0 \mathrm{mw} / \mathrm{m}^{2}$. Several possible operating points could be selected. For flxed neurron wall loading, $\left\langle>-2.0 \mathrm{mw} / \mathrm{m}^{2}\right.$, the operating point with the lowest current is located at $I_{p} \approx$ $23 \mathrm{MA}$, and $c_{t} \approx 2.68$. The lower 11 wit on the current in ehis case is due only to the soft density limit. The plasma $Q$ is 21 at this polnt, with a current drive power requirement, $P_{C D}$ $170 \mathrm{MW}$, and a beam energy requirement, $E_{b}-2.7$ $\mathrm{MeV}$. Alternatively, a high current operating point with the same wall loading exists at $I_{p}=$ $36 \mathrm{MA}$ and $C_{7}-3,08$. The plasma gain at thls point is $Q-28$ with current drive requirements, $P_{C D}-120 \mathrm{MH}$ and $\mathrm{E}_{\mathrm{b}}-1.4 \mathrm{MeV}$. In thls case the upper bound on the current, for E1xod wall loading, is sot by tho beta linit. A moro detailed list of parameters for an intermediato point are given In Table 3.

We note that the safety factor, at 95 flux, for the operating point in Table 3 . Is ruite a bit righer than in the ITER design $\left(q_{95}=5.3\right.$ compared with $q_{99}-3.2$ in (TER). Since ripple Induced losses of fast alphas scale strongly with the safety factor, the use of ferromagnetic inserts wight be necessazy to reduce the ripple for low current operation. Our calculations have not included fast alpha losses, under the assumption chac the required low level of $r i p p l e$ can be incorporated in the design.

The SOPCON shown in Fig. 3 was generated with the same assumptions as for Flg. 2 except chat both the density and temperature (and therefore the pressure) profiles were assumed to

Table 3. Steady State Operating Point

\begin{tabular}{|c|c|}
\hline$P_{Q}$ eus (MW] & $\begin{array}{c}3500 \\
26\end{array}$ \\
\hline$\left\langle s>\left(\mathrm{MH} / \mathrm{m}^{2}\right\}\right.$ & 2.0 \\
\hline$P_{n b}\left(P_{L h}\right)(\mathrm{NW})$ & $110(22)$ \\
\hline$T_{*}\left(T_{1}\right)[\mathrm{keV}]$ & $19(18)$ \\
\hline$n_{0}\left(n_{t r}\right)\left(10^{20} m^{-3}\right)$ & $0.64(0.69)$ \\
\hline$\beta\left(C_{T}\right)\{8\}$ & $4.0(2.7)$ \\
\hline$\theta_{\mathrm{p}}\left(\dot{f}_{\mathrm{pth}}\right)$ & $1.31(0.99)$ \\
\hline$n_{0}\left(n_{21}\right)\left[10^{10} m^{-3}\right]$ & $3.0(0.45)$ \\
\hline$z_{\text {ett }}\left(z_{j}\right)$ & $1.5(8.0)$ \\
\hline$T_{\mathrm{E}}\left({ }_{\mathrm{HA}}\right)[5]$ & $2.2(30)$ \\
\hline$I_{p}\left(I_{b_{2}}\right)[M A]$ & $25(7.5)$ \\
\hline$I_{n b}\left(I_{2 n}\right)[M A]$ & $14.7(2.8)$ \\
\hline$\gamma_{n b}\left(\gamma_{d n}\right) \quad\left[10^{20} \mathrm{~A} / \mathrm{Wm}^{2}\right\}$ & $0.65(0.50)$ \\
\hline$q_{g s}\left(q_{0}\right)$ & $5.3(1.05)$ \\
\hline$N_{11 . L h}\left(\Delta N_{11}\right)$ & $1.6(0.1)$ \\
\hline$E_{n b}(\mathrm{MeV})$ & 2.1 \\
\hline
\end{tabular}




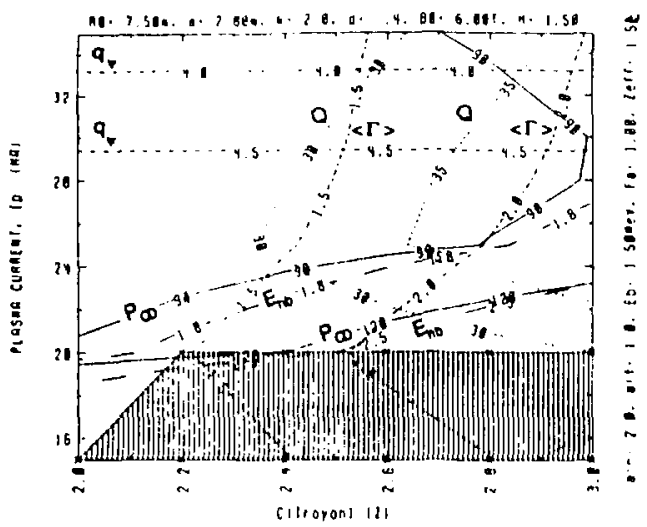

Figure. 3. SOPCON with peaked density and temperature profiles.

be more peaked, $a_{n}=2.0$ and $a_{p}=1.0$. This shows the improvement in reactor performance which could be achieved If methods for central fueling and heating were fully developed. For the same intermediate current, $I_{p}-25 \mathrm{MA}$ as in Table 3., and Troyon coefficient. $C_{1}-2.88$ (which may be close to the limit for this pressure prof(le), the plasma $Q$ value increases to $Q-37$ with the corresponding decrease in current drive power, $P_{C O}-90 \mathrm{MW}$ at an average wall loading, $\langle\Gamma\rangle-2.0 \mathrm{MW} / \mathrm{m}^{2}$. The beam energy requirement is also somewhat lower, $E_{b}-1.7$ $\mathrm{MeV}$, frum the scaling of Eq. (15).

\section{CONCLUSIONS}

The steady stace operating scenario for ITER leads to viable plasma parameters for a tokamak power reactor. in operating point has been identified, below the beta and density limits, in a device with $R_{0}-7.5 \mathrm{~m}$ and $a-2.8 \mathrm{~m}$ which produces $3500 \mathrm{MW}$ of fusion power, an average neutron wall loading $\left\langle\Gamma-2.0 \mathrm{MW} / \mathrm{m}^{2}\right.$ with $a$ plasma $Q-26$. Preliminary reactor economics analysis indicaces that an operating point with higher power density may need to be selected for economically attractive reactor operation. The current is provided by neutral bearn injection in the plasma core, lower hybrid slow waves in the outer regions and bootstrap current. The neutral beam power required is $P_{m b}-110 \mathrm{MW}$ at a deuterlum beam energy of $E_{n b}=2.1$ Mev. The lower hybrid power requirement is $P_{t h}-22 \mathrm{MW}$. The lower hybrid frequency should be high ( $f_{\mathrm{th}} \approx$ $8 \mathrm{GHz}$ ) to avoid both damping on alphas and parametric instabilities. A He-cooled $\mathrm{Li}_{2} \mathrm{O}$ blanket is used with a total inboard radial chickness of 1.16 m. A PF coil set has been found which produces an equilibrius with $x_{95}-$
2.0 and $\delta_{93}-0.4$ at the 958 flux surface. The total scared energy in the $P F$ set is approximately $12 \mathrm{GJ}$. A TF coll set has been examined using $\mathrm{Nb}_{3} \mathrm{Sn}$ conductor, which produces a 6 T field on the geometric axis of the plasma. The maximum field on the inner leg of the TF coil is approximately $14 \mathrm{~T}$.

\section{ACKNOWLEDGEMENT}

Work performed under the auspices of the U.S. Department of Energy by the Lawrence Livermore National Laboratory under contract number $W-7405-E N G-48$.

\section{REFERENCES}

1. ITER Terms of Reference in "Establishment of ITER: Kolevant Documents", IAEA (1988), p.35.

2. F. Troyon, et al., Plasma Phys, and Cont. Fusion 26, 209 (1984).

3. M. Creenwald, et al, "A New Look at Density Limits in Tokanaks," MIT Report PFC-JA-86-22 (1986).

4. P. J. Goldston, Plasma Phys, and Cont. Fusion 26. 98 (1984).

5. R. Parker, Nuc. Fus, 25, 1127 (1985).

6. A. Gibson et al.. "Plasma Performance in JET, Achievements and Projections," Fifteenth European Conference on Controlied Fusion and Plasma Heating, Dubrovnik, May 16-20, 1988.

7. M. Porkolab, IEEE Trans, PIasma Sci. PS-2?. 107 (1984).

8. N. J. Fisch, Phys. Rev. A24, 3245 (1981).

9. P. T. Bonoll and M. Porkalab, "Modeling of Lower Hybrid Current Drlve in ITER," presented at the ITER Specialists Meeting on Current Drive and Heating, Garching June 1988.

10. J. D. Gaffey, J. Plasma Phys, 16, 149 (1979).

11. D. R. Mikkelsen and C. D. Singer, Nucl. Tech./Fusion 4., 237 (1983).

12. R. S. Devoto, K. Tani and M. Azum1, "Computation of Self-Consistent 2D MHD with Neutral-Beam and Bootstrap Currents in Elongated Plasmas," presented at the $15^{\text {th }}$ European Conference on Controlled Fusion and Plasma Heating. Dubrovnik 1988.

13. A. S. Schlacter, J. W. Stearns, W. S. Cooper, and $R$. E. Olson, "Penetration of an Energetic $D^{\circ}$ Beam Into and ETR Plasma: Current Drive for ITER." Lawrence Berkeley Laboratory report LBL-25369 Revised (July 1988).

14. D. L. Smith, G. D. Morgan et a!., "Blanket Comparison and Selection Study," Argonne National Laboratory report ANL/FPP-84-1, VOL 2, p 6.11-17, (1984).

15. M. E. Fenstermacher, "MUMAK - A Computer Code for Modeling Plasma Power Balance and Current Drive in Tokamaks." Lawrence Livermore National Laboratory Report UCID-21038 (1987?. 